\title{
Melatonin's Effect on the Efficacy of Desmopressin in the Treatment of Enuresis
}

\author{
Pietro Ferrara ${ }^{1,2}$, Annamaria Sbordone ${ }^{2}$, Costanza Cutrona ${ }^{2}$, Francesca Ianniello ${ }^{1}$, Chiara Guadagno ${ }^{2}$, Giacomo Perrone ${ }^{2}$, \\ Antonio Chiaretti ${ }^{1}$, Alberto Verrotti ${ }^{3}$, Vincenzo Di Lazzaro ${ }^{4}$ \\ ${ }^{1}$ Institute of Pediatrics, Catholic University Medical School, Rome, Italy \\ ${ }^{2}$ Service of Pediatrics Campus Bio-Medico University, Rome, Italy \\ ${ }^{3}$ Department of Pediatrics, University of Perugia, Perugia, Italy \\ ${ }^{4}$ Institute of Neurology, Campus Bio-Medico University, Rome, Italy
}

Purpose: This study aims to evaluate and compare the efficacy of exogenous melatonin associated with desmopressin (dDAVP) and dietary recommendations.

Methods: A total of 189 patients were enrolled from the Service of Pediatrics, Campus Bio-Medico University Hospital of Rome, from January 2013 to June 2015. Of the 189 original patients, 153 children, aged between 5 and 14 years (mean age, 8.7 years) were included in the study. After clinical evaluation and a 3-month period of observation without treatment, children were assigned to receive treatment in one of 3 groups: group 1, dDAVP at a dose of $120 \mathrm{mcg}$ a day (Minirin); group 2, dDAVP at a dose of $120 \mathrm{mcg}$ and dietary recommendations; or group 3, dDAVP at a dose of $120 \mathrm{mcg}$, dietary recommendations, and melatonin at a dose of $1 \mathrm{mg}$ a day (Melamil plus). Each patient was treated for 3 months.

Results: After the 3 months of therapy, a desiderable response was achieved in 30 of 51 patients (58.82\%) treated with dDAVP, 35 of 53 patients (66.04\%) treated with dDAVP and dietary recommendations, and 35 of 49 patients $(71.43 \%)$ treated with dDAVP, dietary recommendations, and melatonin.

Conclusions: Although not statistically significant, the results show that the association between dDAVP treatment with dietary recommendations and melatonin could be considered a safe and effective treatment of NE. Considering that the statistically insignificant results might be due to the small sample size, the study will be continued to increase the number of subjects.

Keywords: Melatonin; Enuresis; Child; Treatment; Desmopressin

- Research Ethics: This study was conducted in accordance with the regulatory standards of Good Clinical Practice and the Declaration of Helsinki and was approved by the Institutional Review Board of Campus Bio-Medico University Hospital.

- Conflict of Interest: No potential conflict of interest relevant to this article was reported.

\section{INTRODUCTION}

Nocturnal Enuresis (NE) is a very common disorder among children. According to the International Children Continence Society (ICCS), NE is defined as intermittent incontinence oc- curring exclusively during sleep periods. NE should not be used to refer to daytime incontinence [1]. According to the Diagnostic and Statistical Manual of Mental Disorders, 5th ed., NE is defined as repeated voiding of urine into a bed or clothes while asleep by children older than 5 years, at least twice a week for 3

Corresponding author: Pietro Ferrara (iD http://orcid.org/0000-0001-9449-3464 Institute of Pediatrics, Catholic University Medical School, L.go Francesco Vito, 1, 00168, Rome, Italy

E-mail: pietro.ferrara@unicatt.it / Tel: +39-6-30154348 / Fax: +39-6--3383211

Submitted: January 11, 2016 / Accepted after revision: February 29, 2016 
consecutive months [2].

Children without daytime urinary symptoms have monosymptomatic-NE (MNE), while those who experience symptoms like urgency, frequency, or daytime urinary incontinence have non-MNE [3].

NE can be also classified as primary or secondary: primary MNE (PMNE) occurs in a child who has never attained nocturnal urinary continence, whereas in secondary MNE (SMNE) the disorder appears after the child has achieved a period of at least 6 months of nocturnal dryness. The former condition seems to be related to impaired sleep arousal, nocturnal polyuria, a small nocturnal bladder capacity, or a combination of these factors, while the latter appears to correlate with psychological stress, constipation, urinary tract infections, urge symptoms, diabetes, or obstructive sleep apnoea [4].

The prevalence of NE is above $10 \%$ among 6 year-olds, around 5\% among 10 year-olds, and $0.5 \%-1 \%$ among teenagers and young adults [5-9]. An Italian epidemiological study reported an overall NE prevalence of 3.8\%, decreasing proportionately with age [10].

The aetiology of the disorder is multifactorial. Indeed, nocturnal NE is a result of a combination of several factors, such as nocturnal polyuria, impaired arousal mechanism, genetic factors, and detrusor overactivity. These children do not secrete adequate antidiuretic hormone at night, have a small bladder capacity and nocturnal detrusor overactivity. They also have a positive family history of NE and they are more difficult to awake from sleep than dry-children [11].

Even if spontaneous remission is frequent, management of $\mathrm{NE}$ is important because if left untreated, the disorder can have a deep impact on a child's social development, emotional state, and self-esteem [12-14].

Both pharmacological and psychological/behavioural interventions can be used. The former involves the use of desmopressin, tricyclic antidepressants, and anticholinergic drugs, whereas the latter includes urotherapy, bedwetting alarms, behavioural interventions, and alternative medicine $[15,16]$.

The first line therapy for patients with PMNE associated with nocturnal polyuria and normal bladder function is desmopres$\sin (\mathrm{dDAVP})$, which is a synthetic vasopressin analogue, available as a fast-melting oral lyophilisate (MELT).

Even with proper treatment, a number of children do not respond to dDAVP; therefore, other therapies are worth exploring.

The disorder is associated with difficulties in arousal from the sleep and low nocturnal level of vasopressin. These circadi- an rhythms (sleep-wake cycle and release of endogenous arginine vasopressin $[\mathrm{AVP}]$ ) may play an important role and are associated with circadian melatonin excretion. Moreover, a relationship has been suggested between MNE, difficulties with arousal from sleep, disturbance in circadian rhythms, and nocturnal vasopressin and melatonin secretions [17].

Compared with dry-children, those with MNE have lower peak melatonin levels $(\mathrm{pg} / \mathrm{mL})$ at $4.00(7.00$ [1.95-9.4] vs. 8.20 [4.0-23.0]) and higher levels at $24.00(5.10$ [2.9-15] vs. 4.50 [1.6-6.0]) [18].

Considering these observations, as well as the fact that melatonin plays an important role in the treatment of several sleep and circadian disorders, melatonin could also be an effective therapeutic remedy in the treatment of MNE [19-21].

The aim of this study is to evaluate and compare the efficacy of exogenous melatonin associated with different combinations and levels of dDAVP treatment and dietary recommendations.

\section{MATERIALS AND METHODS}

\section{Patients}

A total of 189 patients were enrolled from the Service of Paediatrics, Campus Bio-Medico University Hospital of Rome, from January 2013 to June 2015. Of these, 25 were excluded and 11 were lost to follow up.

Hence, the study included 153 children, aged between 5 and 14 years (mean age, 8.7 years).

To be eligible for inclusion, patients had to meet the ICCS definition of NE, while exclusion criteria included treatment within the previous 3 months, non-MNE, SMNE, and history of urinary tract infections.

The eligible children and their families were asked to participate in the study at the end of the clinical evaluation.

All patients had a clinical and anamnestic evaluation. Bladder function was investigated using a bladder diary to collect information about the time and the number of occasions of urination, urinary volume, volume of fluid intake, urinary leakage, activities that provoked it, and signs of urge incontinence. The child's parents kept the diary for 3 months after the enrolment and during the period of observation.

This study was conducted in accordance with the regulatory standards of Good Clinical Practice and the Declaration of Helsinki (1996) and was approved by the Institutional Review Board of Campus Bio-Medico University Hospital. 


\section{Study Design}

After clinical evaluation and after a 3-month period of observation without treatment, children were randomly assigned to one of 3 treatment groups: group 1, dDAVP at a dose of 120 mcg a day (Minirin melt-oral lyophilisate, Ferring Pharmaceuticals, Saint Prex, Switzerland); group 2, dDAVP at a dose of $120 \mathrm{mcg}$ and dietary recommendations; or group 3, dDAVP at a dose of $120 \mathrm{mcg}$, dietary recommendations and melatonin at a dose of $1 \mathrm{mg}$ a day (Melamil plus). The dose of dDAVP was gradually increased to $240 \mathrm{mcg}$, if needed. A simple sequential randomization procedure was used.

The dietary recommendations consisted of a list of recommended food, food not recommended in the evening, and food not recommended at all. The list was designed by reviewing the relevant literature (Table 1) [22]. Parents were also given some advice, such as double voiding at bedtime or fluid restriction in the evening.

Each patient was treated for 3 months. During the 3-month period of treatment, all patients and their parents were asked to keep a NE calendar depicting the wet and the dry nights and a food diary. During the follow-up, families were called to verify their adherence and responses to the therapy and dietary recommendations.

Table 1. List of dietary advises in children with nocturnal enuresis

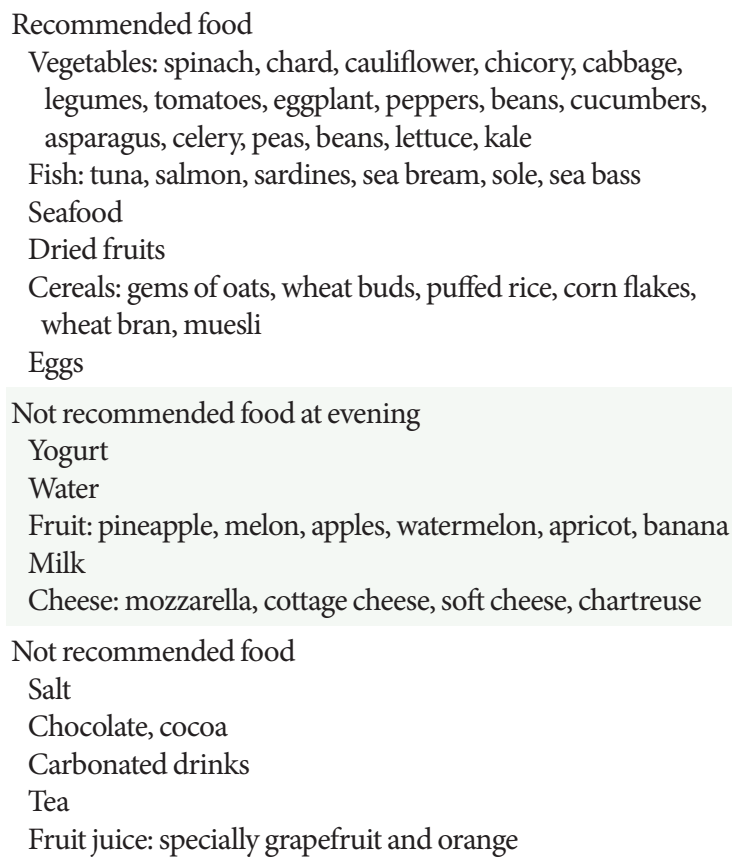

\section{Outcome Measures}

The primary outcome was the improvement in the frequency of bedwetting per week and the efficacy of the 3-month period of treatment. Moreover, the number and percentage of nonresponders, partial responders and full responders were evaluated after therapy in each group. Nonresponse is defined as a $0 \%$ to $49 \%$ decrease, partial response is defined as a $50 \%$ to $89 \%$ decrease, full response is defined as a $90 \%$ or greater decrease in wet nights monthly [23]. We also considered the occurrence of adverse effects.

\section{Statistical Analysis}

Data were expressed as mean \pm standard deviation and percentage. A paired-samples t-test and an independent-samples t-test were used for continuous variables; the chi-square test was used for categorical variables. The significance level was set at $\mathrm{P}<0.05$.

\section{RESULTS}

Of the 189 initially enrolled patients, 25 (13\%) were excluded for the following reasons: 20 experienced daytime symptoms, 3 had undergone therapy with DDAVP in the previous 3 months, 2 had secondary NE. Of the 164 patients who underwent randomization, 11 were lost to follow-up.

Thus, 153 children were included in our study. Of these, 110 (71.9\%) were male and 43 (28.1\%) were female, aged between 5 and 14 years (mean age, 8.8 years). Fifty-one patients were assigned to receive dDAVP (group 1), 53 patients received dDAVP and dietary recommendations (group 2), and 49 received dDAVP, dietary recommendations and melatonin (group 3) (Fig. 1). There were no differences in sex, age or family history of enuresis between the 3 groups.

The severity of NE was measured as the mean number of wet nights per week. After the observation period, this was $6.5 \pm 0.7$ in group 1, $6.3 \pm 0.9$ in group 2, and $6.28 \pm 1.12$ in group 3 .

The mean number of wet nights after the treatment was $2.4 \pm 2.8$ in the children treated with dDAVP, $2.3 \pm 2.6$ in those treated with $\mathrm{DDAVP}$ and dietary recommendations, and $2.67 \pm$ 2.68 in those receiving dDAVP, dietary recommendations and melatonin.

After the 3 months of therapy there was a significant difference between wet nights before and after treatment in all of the three groups $(\mathrm{P}<0.01)$.

After the 3 months of therapy a response was achieved in 30 out of 51 children (58.82\%) in group 1, 35 of 53 children 


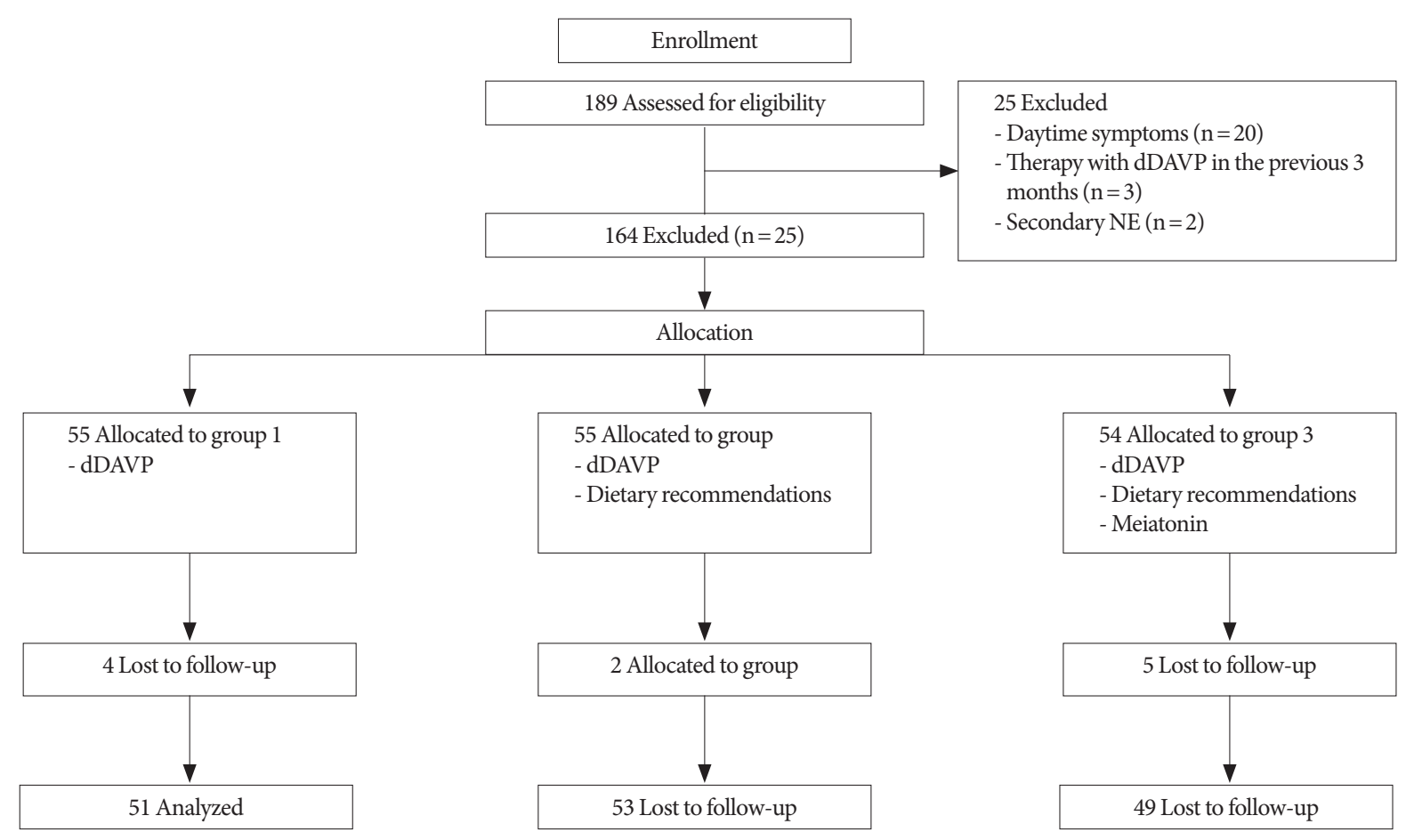

Fig. 1. CONSORT (consolidated standards for reporting of trials) flow diagram. dDAVP, desmopressin; NE, nocturnal enuresis.

Table 2. Number and percentage of responders

\begin{tabular}{lcc}
\hline Group & Responders & Nonresponders \\
\hline 1 & $30(58.82)$ & $21(41.18)$ \\
Full & $27(52.94)$ & \\
Partial & $3(5.88)$ & $18(33.96)$ \\
2 & $35(66.04)$ & \\
Full & $31(58.49)$ & $14(28.57)$ \\
Partial & $4(7.55)$ & \\
3 & $35(71.43)$ & \\
Full & $27(55.10)$ & \\
Partial & $8(16.33)$ & \\
\hline
\end{tabular}

Group 1, desmopressin (dDAVP) at a dose of $120 \mathrm{mcg}$ a day (Minirin); group 2, dDAVP at a dose of $120 \mathrm{mcg}$ and dietary recommendations; group 3, dDAVP at a dose of $120 \mathrm{mcg}$, dietary recommendations, and melatonin at a dose of $1 \mathrm{mg}$ a day (Melamil plus).

(66.04\%) in group 2, and 35 of 49 children $(71.43 \%)$ in group 3. These differences are not statistically significant $(\mathrm{P}=0.41)$ (Table 2). The results are not statistically significant when comparing group 1 with group $3(\mathrm{P}=0.18)$.

A full response was achieved in 27 children in group 1 (52.94\% of all the children of the group and $90 \%$ of the responders), 31 children in group 2 (58.49\% of all the children of the group and $88.57 \%$ of the responders), and 27 children in group 3 (55.10\% of all the children of the group and $77.14 \%$ of the responders).

A partial response was achieved in 3 children in group 1 (5.88\% of all the children of the group and $10 \%$ of the responders), 4 children in group 2 ( $7.55 \%$ of all the children of the group and $11.43 \%$ of the responders), and 8 children in group 3 (16.33\% of all the children of the group and $22.86 \%$ of the responders).

The odds of response is the ratio between the probability to respond to treatment and the probability to not. The odds of response for children in G3 is $2.496=(35 / 49) /(14 / 49)=(0.714 / 0.286)$. The odds of response for children in G1 is $1.427=(30 / 51) /(21 / 51)$ $=(0.588 / 0.412)$. The odds ratio is the ratio between the 2 odds: $2.496 / 1.427=1.75$.

No adverse effects were reported in the 153 children enrolled in the study.

\section{DISCUSSION}

Since NE is a disorder with a complex and multifactorial aetiology, various types of interventions can be used. The pathogenetic factors are detrusor overactivity, difficulties with arousal from sleep, and nocturnal polyuria.

This study evaluated a new approach to therapy, using melatonin in association with dDAVP and dietary recommendations. 
Melatonin is a hormone produced by the pineal gland and controlled by the suprachiasmatic nuclei. Its main function is to regulate the circadian rhythm [24].

The levels of the hormone are high during the night, with a peak at 02:00-03:00 AM, and they decrease in the morning. The time of the peak seems to coincide with the time of urine loss in MNE patients, and this means that there might exist a relationship between the production of the hormone and bedwetting. Comparing melatonin levels in saliva between enuretic patients and a control group, Ardura-Fernandez et al. [18] found differences between the groups.

Moreover, melatonin can affect not only the sleep-wake cycle, but also other circadian rhythms, like the release of endogenous AVP; abnormal circadian AVP levels in MNE patients compared to nonenuretic children are described by Rittig et al. [25]. It is also known that exogenous melatonin can shift the phases of circadian rhythms [26].

Another study evaluated the efficacy of exogenous melatonin in enuretic children, leading to the following results: a shift in peak-time and height of the melatonin profile in the group who received melatonin but no changes in enuresis frequency. However, the population of the study was small and consisted of a select group of patients resistant to all other forms of therapy [27].

This study represents the first attempt to evaluate the association between melatonin, dDAVP, and dietary recommendations.

There are some limitations in the study to point out. The sample size was too small and prolonging the research in order to see a more significant rate of resolution is necessary. Moreover, the sleep cycles of the patients were not evaluated in a systematic way. It could be interesting to investigate any possible change in the sleep habits of the children taking melatonin, using, for example, a validated questionnaire. Are these children harder to wake-up? Do their school performances change?

The results show a higher response rate in group 3 vs. group 2 vs. group 1 (71.43\% of responders - full and partial - in group 3 versus $66.04 \%$ in group 2 vs. $58.82 \%$ in group 1 ).

However, although the preliminary results are not statistically significant, they show a higher rate of responders in the group treated with melatonin. Therefore, these interim results are promising. Moreover, the results may not be statistically significant due to the small sample size.

Another important result is the lack of adverse effects, suggesting that the use of melatonin could be considered as a good and safe treatment for NE. Therefore, the study may be useful to determine a new intervention in order to have a wider spectrum of treatment choices in enuretic patients.

In conclusion, MNE is a common paediatric condition. However, despite several treatment options, a number of children do not respond to therapy, which can be inconvenient and distressing to both children and their families [28]. Moreover, as was shown in several recent studies, persistence of NE can also have some medical consequences [29-31].

Therefore, other therapeutic approaches are worth exploring.

This is the first time the association between exogenous melatonin, dDAVP and dietary recommendations has been evaluated in the treatment of MNE.

Even though the results are not statistically significant, they show that the association between dDAVP and dietary recommendation and melatonin could be considered a good and safe treatment of NE.

Considering that this could be due to the small sample size, further studies with more participants are needed.

\section{REFERENCES}

1. Austin PF, Bauer SB, Bower W, Chase J, Franco I, Hoebeke P, et al. The standardization of terminology of lower urinary tract function in children and adolescents: update report from the Standardization Committee of the International Children's Continence Society. J Urol 2014;191:1863-5.e13.

2. American Psychiatric Association. Diagnostic and statistical manual of mental disorders, 5th ed (DSM-V). Washington, DC: American Psychiatric Publishing; 2013.

3. Deshpande AV, Caldwell PH. Medical management of nocturnal enuresis. Paediatr Drugs 2012;14:71-7.

4. Robson WL, Leung AK, Van Howe R. Primary and secondary nocturnal enuresis: similarities in presentation. Pediatrics 2005; 115:956-9.

5. Neveus T, Läckgren G, Tuvemo T, Hetta J, Hjalmås K, Stenberg A. Enuresis--background and treatment. Scand J Urol Nephrol Suppl 2000;(206):1-44.

6. Bakker E, van Sprundel M, van der Auwera JC, van Gool JD, Wyndaele JJ. Voiding habits and wetting in a population of 4,332 Belgian schoolchildren aged between 10 and 14 years. Scand J Urol Nephrol 2002;36:354-62.

7. Fergusson DM, Horwood LJ, Shannon FT. Factors related to the age of attainment of nocturnal bladder control: an 8-year longitudinal study. Pediatrics 1986;78:884-90. 
8. Howe AC, Walker CE. Behavioral management of toilet training, enuresis, and encopresis. Pediatr Clin North Am 1992;39:413-32.

9. Yeung CK, Sihoe JD, Sit FK, Bower W, Sreedhar B, Lau J. Characteristics of primary nocturnal enuresis in adults: an epidemiological study. BJU Int 2004;93:341-5.

10. Chiozza ML, Bernardinelli L, Caione P, Del Gado R, Ferrara P, Giorgi PL, et al. An Italian epidemiological multicentre study of nocturnal enuresis. Br J Urol 1998;81 Suppl 3:86-9.

11. Robson WL. Clinical practice: evaluation and management of enuresis. N Engl J Med 2009;360:1429-36.

12. Butler RJ. Annotation: night wetting in children: psychological aspects. J Child Psychol Psychiatry 1998;39:453-63.

13. Rogers J. An overview of the management of nocturnal enuresis in children. Br J Nurs 2003;12:898-903.

14. Theunis M, Van Hoecke E, Paesbrugge S, Hoebeke P, Vande Walle J. Self-image and performance in children with nocturnal enuresis. Eur Urol 2002;41:660-7.

15. Caldwell PH, Nankivell G, Sureshkumar P. Simple behavioural interventions for nocturnal enuresis in children. Cochrane Database Syst Rev 2013;(7):CD003637.

16. Ferrara P, Marrone G, Emmanuele V, Nicoletti A, Mastrangelo A, Tiberi E, et al. Homotoxicological remedies versus desmopressin versus placebo in the treatment of enuresis: a randomised, doubleblind, controlled trial. Pediatr Nephrol 2008;23:269-74.

17. van Gool JD, Nieuwenhuis E, ten Doeschate IO, Messer TP, de Jong TP. Subtypes in monosymptomatic nocturnal enuresis. II. Scand J Urol Nephrol Suppl 1999;202:8-11.

18. Ardura-Fernandez J, Andres De Llano JM, Garmendia-Leiza JR, Agapito T. Melatonin rhythm in children with enuresis. BJU Int 2007;99:413-5.

19. Kennaway DJ. Potential safety issues in the use of the hormone melatonin in paediatrics. J Paediatr Child Health 2015;51:584-9.

20. Kennaway DJ, Wright H. Melatonin and circadian rhythms. Curr Top Med Chem 2002;2:199-209.

21. Szeinberg A, Borodkin K, Dagan Y. Melatonin treatment in adolescents with delayed sleep phase syndrome. Clin Pediatr (Phila)
2006;45:809-18.

22. Ferrara P, Del Volgo V, Romano V, Scarpelli V, De Gara L, Miggiano GA. Combined dietary recommendations, desmopressin, and behavioral interventions may be effective first-line treatment in resolution of enuresis. Urol J 2015;12:2228-32.

23. Nevéus T, von Gontard A, Hoebeke P, Hjalmås K, Bauer S, Bower W, et al. The standardization of terminology of lower urinary tract function in children and adolescents: report from the Standardisation Committee of the International Children's Continence Society. J Urol 2006;176:314-24.

24. Hardeland R, Cardinali DP, Srinivasan V, Spence DW, Brown GM, Pandi-Perumal SR. Melatonin: a pleiotropic, orchestrating regulator molecule. Prog Neurobiol 2011;93:350-84.

25. Rittig S, Knudsen UB, Nørgaard JP, Pedersen EB, Djurhuus JC. Abnormal diurnal rhythm of plasma vasopressin and urinary output in patients with enuresis. Am J Physiol 1989;256(4 Pt 2):F664-71.

26. Skene DJ, Lockley SW, Arendt J. Use of melatonin in the treatment of phase shift and sleep disorders. Adv Exp Med Biol 1999;467:7984.

27. Merks BT, Burger H, Willemsen J, van Gool JD, de Jong TP. Melatonin treatment in children with therapy-resistant monosymptomatic nocturnal enuresis. J Pediatr Urol 2012;8:416-20.

28. Ferrara P, Romano V, Cortina I, Ianniello F, Fabrizio GC, Chiaretti A. Oral desmopressin lyophilisate (MELT) for monosymptomatic enuresis: structured versus abrupt withdrawal. J Pediatr Urol 2014; 10:52-5.

29. Ferrara P, De Angelis MC, Caporale O, Malamisura M, Del Volgo V, Vena F, et al. Possible impact of comorbid conditions on the persistence of nocturnal enuresis: results of a long-term follow-up study. Urol J 2014;11:1777-82.

30. Guzelsoy M, Demirci H, Coban S, Belkiz Gungör B, Ustunyurt E, Isildak S. Impact of urinary incontinence on quality of life among residents living in Turkey. Urol J 2014;11:1447-51.

31. Shadpour P, Shiehmorteza M. Enuresis persisting into adulthood. Urol J 2006;3:117-29. 